\title{
MODELO CRÍTICO DE EXPANSÃO DO SETOR IMOBILIÁRIO BRASILEIRO AO PROGRAMA MINHA CASA MINHA VIDA
}

\author{
Bruno Xavier Martins ${ }^{1}$ \\ Universidade de São Paulo
}

\begin{abstract}
Resumo: Este trabalho tem por objetivo traçar um percurso do mercado imobiliário brasileiro que vai da abertura de capital de suas principais incorporadoras nos anos de 2006 e 2007 até o lançamento do Programa Minha Casa Minha Vida no começo de 2009, como medida emergencial de resposta à grande crise de 2008 e ao colapso já deflagrado no próprio setor a partir da entrada dessas incorporadoras na bolsa de valores. Buscamos, assim, entender as relações críticas que se desenrolaram desse processo de comunhão entre o ritmo de remuneração do capital financeiro mundial e o endividamento geral da sociedade brasileira. O Programa Minha Casa Minha Vida parece dar um forte impulso ao processo de internalização do funcionamento do capital fictício no Brasil, em que o Estado nacional, incorporadoras e indivíduos passam a ter na dívida a única forma (crítica) de inserção e permanência no mercado.
\end{abstract}

Palavras-chave: Programa Minha Casa Minha Vida; Endividamento; Setor Imobiliário; Capital Fictício; Urgência.

\section{FROM BRAZIL'S CRISIS-RIDDEN MODEL OF REAL ESTATE GROWTH TO THE MINHA CASA MINHA VIDA PROGRAM}

Abstract: This paper aims to describe the development of Brazil's real estate market from the public listing of major developers in the years 2006 and 2007 until the release of Minha Casa Minha Vida in early 2009, as an emergency measure in response to the major crisis 2008 and to the collapse caused by the sector itself after the wave of IPOs. We seek, therefore, to understand the critical relationships that unfolded from this process of convergence between global finance capital's profits and the widespread indebtedness of Brazilian society. The Minha Casa Minha Vida program seems to give a strong boost to the operation of fictitious capital in Brazil, where by the national state, developers and individuals rely on debt as the only way (a critical way) of entering and remaining in the market.

Keywords: Minha Casa Minha Vida; Indebtedness; Real Estate; Fictitious Capital; Urgency.

\footnotetext{
${ }^{1}$ Geógrafo e economista. Mestrando no Programa de Pós-Graduação em Geografia Humana da Universidade de São Paulo e bolsista FAPESP. Contato: bruno_x_martins@hotmail.com.
} 
Certo boom imobiliário tornou-se claro no Brasil de 2007 em diante, causando uma alta nos preços dos imóveis e evidenciando, mais uma vez, o problema histórico da moradia no Brasil. Políticas de caráter anticíclicas, que visavam contornar os problemas decorrentes da crise de 2008, passaram a ser mais comumente aplicadas, sobretudo após 2009. Estava dado o cenário no qual um novo estado de emergência econômico justificava as ações governamentais do Estado brasileiro: a crise de 2008, o déficit habitacional crônico e a necessidade de manter o Brasil como receptor de dinheiro mundial em busca de remuneração se articulam a partir de uma política anticíclica editada em caráter de urgência - o Programa Minha Casa Minha Vida (PMCMV).

Uma urgência, entretanto, sob a forma de políticas anticíclicas, mostra-se mais premente que as demais: a remuneração do capital financeiro internacional que então fluía para o país dentro das incorporadoras brasileiras. A crise de 2008 passou a funcionar como a justificativa econômica para a realização do PMCMV e o déficit habitacional (que é real) como a justificativa ideológica ao programa, uma vez que permitira realizar o "sonho da casa própria". Eis o cenário sobre o qual o PMCMV passou, juntamente com o bom momento do mercado interno, o qual serviu de lastro ao capital fictício começava a entrar mais intensamente no país em busca das promessas do setor imobiliário.

Assim, o PMCMV foi editado de última hora no gabinete da Casa Civil, sem a participação de movimentos populares nem uma consulta ao Conselho Nacional de Cidades do Ministério das Cidades, sendo apresentado ao mesmo tempo como programa de crescimento econômico e de atendimento à demanda social. Mas, o que se oculta é justamente a função primordial à qual o projeto pretendeu atender, trazer de volta o capital internacional para as incorporadoras após terem fugido para seus mercados de segurança depois da crise de 2008, com a promessa de estabilidade e de alta remuneração.

Até então a alta taxa de juros brasileira era um dos principais fatores responsáveis pela captação da liquidez mundial no país, no entanto a crise mundial de 2008 trouxe insegurança para os investidores, que sugaram seus capitais de todo o mundo e os destinaram aos papéis da dívida americana, mesmo que a juros negativos. $\mathrm{O}$ Brasil já não poderia depender unicamente de sua política monetária para a atração desse capital internacional e:

após a crise, as políticas de suposta inclinação keynesiana e de dinâmica territorialmente expansionista ganharam espaço ainda maior e desempenharam bem a função que os sucessivos aumentos na taxa básica de juros até então vinham desempenhando sozinhos (SIMONI, 2013, p. 239).

Explorar o potencial do mercado interno passou a ser prioridade para o governo, no intuito de atrair o capital internacional, que enxergaria nos setores estratégicos do 
país, como a construção civil - a partir da qual se exerce um grande dinamismo entre os diversos setores da economia -, a oportunidade de vincular sua estabilidade econômica às altas expectativas de remuneração do capital às quais se destinaria às incorporadoras.

Assim, a pesquisa detectou três importantes momentos para refletirmos a respeito do contexto do mercado imobiliário brasileiro no século XXI em relação ao surgimento do Programa Minha Casa Minha Vida: o primeiro deles, a abertura de capitais das incorporadoras a partir de 2006 e 2007 e a consequente expansão geográfica dessas empresas por todo o território nacional e para o chamado segmento econômico, agora guiadas pelas necessidades de reprodução do capital financeiro internacional; o segundo, a crise dos subprimes no final de 2008 com o epicentro nos EUA, que promoveu a retração dessas empresas aos seus mercados de origem e a consequente perda de grande quantidade de investimentos feitos em landbanks fora dos mercados centrais a partir do dinheiro captado com a realização de seus IPO's ${ }^{2}$; e, finalmente, o surgimento do Programa Minha Casa Minha Vida, como uma medida de caráter anticíclico em resposta à crise supracitada, que articula um problema social - o déficit habitacional - às necessidades do mercado.

\section{Abertura de capital das incorporadoras brasileiras ${ }^{3}$}

Boa parte dos R $\$ 23$ bilhões captados por meio das ofertas de ações na bolsa de valores entre os anos de 2006 e 2007 serviram para comprar terrenos e lançar imóveis. Desde então, o número de novos empreendimentos mais que triplicou, ao passo que, até o final de 2011, tais empresas não haviam sequer gerado caixa (conta que registra o valor dos recursos imediatamente disponíveis). Os dados são alarmantes: entre 2008 e 2011 o endividamento das principais incorporadoras aumentou 134\%, chegando em 2011 a uma relação dívida/patrimônio de $68 \%{ }^{4}$. Parece haver uma relação direta entre a expansão dessas empresas (e da economia como um todo) e o grau de endividamento das mesmas.

Desde o fim do BNH (Banco Nacional de Habitação), em 1986, o segmento imobiliário de habitação no Brasil entrou num longo jejum de financiamento que durou até 2003, quando voltou a ser capitalizado com a ampliação da faixa de financiamento habitacional compulsório do FGTS (Fundo de Garantia do Tempo de

\footnotetext{
${ }^{2}$ A sigla IPO significa inicial public offering. Ela se refere ao processo de abertura de capital e emissão dos primeiros papéis da dívida de alguma empresa na bolsa de valores.

${ }^{3}$ Algumas leituras foram essenciais para a execução deste item, assim como para a realização de todo o trabalho, mesmo que não aparecendo explicitamente na forma de citações. Por isso a nota. São elas: HARVEY (1990, 1992 e 2004); KURZ (1995 e 1999); OLIVEIRA (1998, 2003 e 2008); MARX (1982 e 1983).

${ }^{4}$ Revista EXAME, 22/02/2012.
} 
Serviço) e do SBPE (Sistema Brasileiro de Poupança e Empréstimos) ${ }^{5}$. O aumento dos prazos de financiamento para a aquisição de um imóvel a partir dessa data e a redução dos juros decorrentes de tal ampliação são reflexos da crença fetichista em torno dos índices positivos de uma economia em crescimento. Além disso, foi criado em 1997 um importante instrumento de mobilização da mercadoria imobiliária: a "alienação fiduciária". Com ela, posse e propriedade só se unificam na mesma pessoa quando ocorre a quitação total da dívida. Até que isso aconteça, o morador, endividado, possui posse direta e propriedade indireta do imóvel, enquanto o credor concentra em si a posse indireta e a propriedade direta, o que facilita a retomada imediata da mercadoria habitação em caso de inadimplência ${ }^{6}$. Tal cisão jurídica ainda não trouxe à tona todas as transformações no cotidiano que, certamente, ainda observaremos através do alcance cada vez mais abrangente da propriedade privada pela população brasileira. De 2006 em diante, as principais incorporadoras realizaram seus IPO's $^{7}$ na bolsa de valores e arrecadaram bilhões de reais em pouquíssimo tempo. "Com a abertura na Bolsa e a injeção de capital, as empresas tiveram que se expandir, tanto geograficamente quanto para faixas do mercado até então inexploradas" (ARANTES \& FIX, 2009). Foram dadas, assim, as bases para a recente expansão do mercado imobiliário no Brasil, só que agora em uma nova dimensão e sob parâmetros de uma economia predominantemente financeirizada. A pesquisa revelou que essa condição aponta para transformações no atual cotidiano urbano brasileiro, cuja sociedade está amplamente endividada, sendo o PMCMV um dos mais importantes elos críticos do processo em curso.

O avanço do setor imobiliário no Brasil, dentro de um contexto crítico da economia mundial de "terceira revolução industrial" (KURZ, 1995), contém particularidades que se ligam ao problema universal. Se para crescer o setor foi obrigado a enquadrar-se na lógica de funcionamento do mercado financeiro, as

\footnotetext{
${ }^{5}$ Para maiores detalhes sobre o funcionamento do sistema de financiamento imobiliário no Brasil, ver o livro O Urbano em Fragmentos: a produção do espaço e da moradia pelas práticas do setor imobiliário, de Adriano Botelho.

${ }^{6}$ São praticamente ficcionais alguns casos reais descritos por Flávia Elaine da Silva Martins, frutos já dessa desmembração jurídica da propriedade privada no Brasil. Seu estudo sobre os leilões de imóveis na cidade de São Paulo reflete isso: "Algumas vezes o leilão só se torna claro para o morador quando começam a chegar os futuros moradores" (MARTINS, 2010, p. 92) Parece, portanto, que os conteúdos sociais são apenas um reflexo das decisões jurídicas, sendo o cotidiano um mero ajuste necessário às normas; e não o contrário, como afirma o Direito. Um momento da realidade que não parece real, mas que se torna mais que real com seu desfecho trágico: toca a campainha da sua casa, você abre a porta e se depara com o comprador de seu próprio imóvel sem que nunca o tenha colocado à venda. Você não pode mais agir sobre o terreno que parecia seu e é obrigado a dar licença àquele que pode comprá-lo.

${ }^{7}$ Lista das empresas do setor de construção civil na Bovespa que abriram capital no período referido: Brascan Residential Properties S.A., em 20/10/06; Camargo Corrêa Desenvolvimento Imobiliário, em 30/01/07; Company S.A., em 01/03/06; Cyrela Brazil Realty S.A. Empreendimentos e Participações, em 01/07/05 e 20/07/06; Even Construtora e Incorporadora S.A., em 30/03/07; Gafisa S.A., em 16/02/06 e 19/03/07; Klabin Segall S.A., em 06/10/06; PDG Realty, em 25/01/07; Rodobens Negócios Imobiliários, em 30/01/07; Rossi Residencial S.A., em 14/02/06 e Tecnisa, em 31/01/07.
} 
questões críticas do padrão mundial de acumulação do capital que colocam em xeque o processo de valorização do valor devem agora ser relacionadas intimamente às especificidades do mercado imobiliário. Mas quais são os reais motivos que fizeram com que esse grande montante de capital financeiro ocioso em busca de valorização se concentrasse nas incorporadoras brasileiras com a abertura de seus capitais entre os anos de 2006 e 2007? Antes, ou melhor, ao invés de dar respostas a uma questão tão espinhosa para a Geografia Urbana atual, cabe refletir a respeito do caminho seguido por Flávia Elaine da Silva Martins (2010) e colocar em confronto possibilidades de análise referentes à questão acima. Para ela,

duas hipóteses são possíveis: a primeira, de que este capital busque exatamente os altos níveis de exploração da construção civil para se valorizar, encontrando na renda da terra um elemento intensificador de suas relações. Nesta opção, renda da terra e do capital adiantado operariam no mesmo sentido. Outra hipótese é que a migração desses investidores para as incorporadoras esteja enquadrada em uma relação crítica de valorização, sendo esse um movimento arriscado por apresentar a estes capitais a necessidade de remuneração da renda da terra e a obrigatoriedade de se envolverem em um ciclo longo de produção. Talvez estas duas opções sejam complementares, sendo que o longo ciclo da produção pode estar sendo resolvido por meio das securitizações (MARTINS, 2010, p. 29).

É indiscutível a existência de uma alta exploração do trabalho no canteiro de obras. Ambas as hipóteses contemplam essa afirmação. Mas, diante de uma economia que parece guiar-se, predominantemente, pelo movimento tautológico do dinheiro (D-D') na esfera financeira, devemos tomar cuidado com a análise que enxerga uma relação automática entre quantidade de trabalhadores e valorização do valor. O ainda, o setor da construção civil é o que mais emprega trabalhadores no Brasil $^{8}$ ? Talvez isso queira dizer que é o que mais emprega trabalhadores no Brasil. Talvez não. O cenário que me parece mais provável mistura as duas hipóteses: o grande montante de dinheiro investido nas incorporadoras indica, ao mesmo tempo, crescimento desse setor e crise de valorização. Por encontrar-se numa relação crítica de valorização, o capital financeiro mundial busca o mercado imobiliário que contém em si a remuneração da renda da terra - uma remuneração baseada na

\footnotetext{
${ }^{8}$ A cadeia da construção imobiliária - estimativa que inclui a cadeia de material de construção para o segmento de habitação - calculou por volta de 3 milhões de trabalhadores para o ano de 2011 (Revista EXAME, 22/02/2012). Os números são frios e não nos dão a verdade das coisas. A alta quantidade de trabalhadores desse setor pode ser tanto uma necessidade de valorização do capital via extração direta da mais-valia, como também pode ser a justificativa ideológica utilizada para a remuneração de um capital financeiro que já não necessita diretamente da extração dessa mais-valia para valorizar-se, utilizando-se, no caso específico, da renda extraída da propriedade dos imóveis como principal motor desse processo.
} 
relação jurídica da propriedade privada e que se sustenta com ou sem a crise do valor. Por isso, não devemos nos esquivar da ideia de simultaneidade entre crise de valorização, acumulação de dinheiro e formação de patrimônio. O momento de crescimento e expansão do mercado imobiliário no Brasil pode ser entendido como a expressão maior da crise do valor; e o fenômeno da crise de 2008 é apenas a queda momentânea do simulacro que sustentou em período anterior aquela expansão crítica nos EUA e no mundo. Sob a lógica de valorização do capital financeiro e, portanto, com parâmetros de rentabilidade deslocados da realidade produtiva do setor da construção civil, constatamos que, independentemente do valor se valorizar por aí ou não, o ritmo necessário à existência do trabalhador no setor se acelera e, consequentemente, o grau de exploração também aumenta. Não é um ou outro.

Já a existência da renda da terra, num histórico de acumulação rentista como o brasileiro, diferencia o segmento da construção civil de outros, pois ela sempre "(...) remunerou os agentes imobiliários muito mais do que qualquer aumento de produtividade interno à construção civil." (MARTINS, 2010, p. 28) Resultado disso é uma composição orgânica do capital mais baixa (TAVARES, 2008, p. 79. In.: MARTINS, 2010, p. 28)

(...) e uma lógica de produção apoiada na manutenção das altas taxas de exploração do trabalho no canteiro de obra, repercutindo em formas aparentemente arcaicas de produção, mas que sabemos, complementares à industrialização (MARTINS, 2010, p. 28).

Tais especificidades do mercado imobiliário que vimos falando, a saber, a importância da renda da terra, a baixa composição orgânica do capital, juntamente com as diferenças na rotação do capital decorrentes dos prazos mais longos que as incorporadoras necessitam para a realização dos ciclos de produção e consumo, fizeram com que "o mercado" não soubesse como avaliar o preço dessas incorporadoras quando da abertura de seus capitais na bolsa de valores. Sendo este um ato inédito até aquele momento - antes do final de 2005 não havia nenhuma empresa do setor de capital aberto -, a cultura patrimonialista brasileira atrelada aos desígnios da renda da terra, como já observado, corroborou para que a forma de avaliação dessas empresas se desse a partir da formação de um banco de terras no 
território nacional ${ }^{9}$. Vê-se, portanto, que a entrada de capitais internacionais pelas incorporadoras esteve assentada não em critérios de capacidade produtiva, mas sim na existência de um lastro rentista: o land bank. O capital financeiro parece fazer uma tábula rasa dos setores da economia nos quais investe seus capitais, impondo a todos, igualmente, “(...) a temporalidade e os parâmetros de rentabilidade próprios do setor financeiro e do atual padrão de acumulação do capital" (FIX, 2011. In: SIMONI, 2013, p. 243)

Isso fez com que as incorporadoras iniciassem uma imensa corrida em busca de terras. A aquisição dos terrenos, porém, ganha novos conteúdos históricos com o processo de financeirização do setor, deixando num segundo plano a tradicional prática de especulação que remunerava o capital a partir da diferença entre o montante pago na aquisição da terra e aquele adquirido na venda.

Não que isso [a conhecida prática especulativa de comprar mais barato para vender mais caro] não pudesse vir a compor parte dos lucros ou mesmo parte das estratégias das empresas, mas o aumento da velocidade de rotação do capital total das empresas prometia lucros mais ajustados às expectativas do segmento com um consequente aumento na captação da liquidez internacional que começava a entrar no espaço econômico nacional pela via dos papéis ofertados pelas grandes incorporadoras (SIMONI, 2013, p. 243).

Altera-se, assim, a função do banco de terras para o segmento das incorporadoras. E é importante atentar-se para isso. A "coisa" é a mesma: terras. Mas possui finalidades diferentes antes e depois do direcionamento do setor pelo capital financeiro. Antes ela servia para fins especulativos, valendo-se do diferencial de renda entre o momento da compra e o da venda, como já fora anunciado; além de servir como reserva para lançamento de unidades futuras. Agora a aquisição do banco de terras serve, primeiramente, como prática necessária para que as incorporadoras consigam captar dinheiro em adiantamento e “(...) a captação dessa liquidez tornou-se, a partir de um determinado estágio, umas das poucas possibilidades de expansão do segmento" (SIMONI, 2013, p. 243). Num contexto

\footnotetext{
9 “Na época dos IPO's e do início do follow-on, de acordo com Ana Maria Castelo, do IBRE, 'os investidores não sabiam muito para onde olhar. Existia já um histórico de acompanhar a empresa, empresas da indústria, empresa de serviços, mas o setor da construção (...) era um setor novo dentro do mercado de capitais. Então, que parâmetro usar? E aí nessa incerteza, um dos parâmetros que eles começaram a usar foi o banco de terrenos (...). Um banco de terrenos bom significa que vai lançar, e aí as empresas começaram a correr para formar esse banco de terrenos, já com o início aí da subida do preço dos terrenos. (...) Só que, de qualquer maneira, isso levou as empresas perceberem que essa é uma estratégia complicada. Houve aí uma desmobilização (...) não que as empresas tenham deixado de ter um banco de terras, mas essa coisa, né, o próprio investidor olhar para o próprio banco de terrenos houve uma mudança importante e começaram a perceber, começaram a olhar lançamentos e vendas" (SIMONI, 2013).
} 
de endividamento crescente, as incorporadoras preferiram seguir a estratégia cega imposta pelo mercado financeiro de aquisição de terras para adiantamento do capital, que era novamente utilizado para aumentar o land bank. No entanto,

a captação com a oferta em bolsa exige a contraparte das empresas de incorporação. A necessidade de tocar as obras e sustentar uma velocidade de lançamentos compatível com a velocidade de aquisição de material (terrenos) é uma delas (SIMONI, 2010, p. 244).

Não que agora não houvesse lançamentos de unidades no setor imobiliário, o que seria infantil afirmar, mas, nesse momento a velocidade da aquisição de terrenos é o que mede o preço das incorporadoras na bolsa de valores e não mais, prioritariamente, a velocidade de vendas (VSO) - como voltará a ser após a crise de 2008. Há, portanto, um descompasso entre a expectativa criada para o setor e a realização dos produtos habitacionais para a venda, sendo este talvez o efeito da relevância dada à formação do banco de terras para a precificação das incorporadoras em relação aos lançamentos, gerando um sistema de endividamento para as incorporadoras que só pode ser saldado a partir da contração de novas dívidas. "Lançar, pagar a dívida e remunerar o capital financeiro acionista eram os três compromissos que essas incorporadoras deveriam saldar num contexto de uma dinâmica expansionista superestimada" (SIMONI, 2010, p. 244-5).

A lógica do ganho futuro chega à produção do imobiliário e do espaço, trazendo grandes impactos para o modo como se dá a vida na cidade. Em função desta lógica de superprodução do espaço, a cidade tende a uma obsolescência ainda mais acelerada, uma vez que se torna necessário reproduzi-la em uma velocidade e escala mais acentuada. Parece ser por essas razões que o endividamento das incorporadoras, e o da sociedade como um todo (Estado, empresas e indivíduos), passa a ser, com o tempo, mais aceitável para a sociedade e para o funcionamento de toda a economia ${ }^{10}$ : empresas driblam as próprias contabilidades como forma de incorporar as dívidas como receitas ${ }^{11}$; Estados nacionais inserem-se nos mercados

\footnotetext{
${ }^{10} \mathrm{O}$ endividamento geral da sociedade não foi sempre uma constante na história do capitalismo: "Para o capital privado do século XIX, arcaico do ponto de vista de hoje, com os seus proprietários pessoais patriarcais e respectivos clãs familiares, vigoravam ainda os princípios da respeitabilidade e da 'solvência', à luz dos quais o recurso crescente ao crédito parecia quase obsceno, quase o 'princípio do fim'; (...). Naturalmente, o capital que rende juros era desde o princípio indispensável como tal ao sistema que se formava, mas não detinha ainda uma parcela decisiva no conjunto da reprodução capitalista; e sobretudo os negócios de 'capital fictício' eram considerados, por assim dizer, típicos do ambiente de charlatanice de vigaristas e "gente desonesta ", à margem do capitalismo autêntico (mas a que já então se juntava a honorável burguesia em tempos de ondas especulativas). Até Henry Ford se recusou por muito tempo a recorrer ao crédito bancário para a sua empresa, pretendendo financiar os seus investimentos apenas com capital próprio" (KURZ, 1995).

${ }^{11}$ Essa é uma importante reflexão para pensarmos o capital fictício dentro das incorporadoras, ou seja, sua forma cega de buscar dinheiro em adiantamento sem necessária correspondência com a economia
} 
internacionais a partir da emissão de suas dívidas públicas; indivíduos possuem no "trabalho futuro" a forma de sociabilidade do presente, contraindo dívidas para as necessidades substanciais da vida muito maiores do que a capacidade que têm de saldá-las.

O que podemos ponderar a partir dessas observações, é que já não importa essencialmente se Estados, indivíduos e empresas possuem dívidas ou não para seguirem atuantes no mercado, mas, antes, que se demonstrem solventes, ou seja, capazes de rolá-las com o intuito de seguir remunerando o capital financeiro. Nesse sentido, parecemos caminhar para uma naturalização cada vez maior do "ser endividado", uma relação necessária de manutenção da forma do capital ao lado de seu conteúdo cada vez mais crítico, ou ainda, de manutenção da reprodução do capital, que falamos acima, que carrega lado a lado acumulação de dinheiro e desvalorização do valor, sendo a divida a esfera financeira do "reengate" efetivado pelo cotidiano na sociedade.

A corrida em busca de terrenos feita a partir da expansão de um grande número de parcerias, fusões e aquisições - expansão necessária das grandes incorporadoras para além dos centros urbanos brasileiros devido à captação de um excessivo capital em seus IPO's -, encontrou fortes limitações no ritmo desejado de dispersão geográfica de suas atividades: "os limites de atuação nessas parcerias diziam respeito ao caráter pouco ajustado dessas pequenas empresas aos padrões contábeis e de gestão das grandes incorporadoras que chegavam do Sudeste" (SIMONI, 2013, p. 246).

A informalidade das parceiras no interior do Brasil - que não respeitavam todos os parâmetros legais exigidos nos grandes centros - e os altos custos resultantes dessa expansão passam a ser problemáticos para a lógica racional de remuneração do capital financeiro. A esperança no aumento de unidades futuras, a concorrência nos mercados centrais e a captação de dinheiro em adiantamento na abertura de capitais são, entre outras, algumas das principais características que provocaram o surto expansionista dessas incorporadoras. Esse movimento, entretanto, ocorreu em resposta ao compromisso que elas firmaram com a remuneração do capital financeiro, colocando-se a necessidade de prever lançamentos futuros para além dos mercados centrais, mesmo que a velocidade de realização de seus produtos ainda não estivesse adequada à velocidade de remuneração imposta pelos critérios abstratos de avaliação do capital financeiro mundial.

A crise mundial de 2008, que abordaremos a seguir, tem importância pela sua dimensão, mas ajuda a esconder a crise que já estava colocada no mercado

real: "Da mesma forma que o crédito, a dívida deve ser analisada não só pela lógica da equivalência estrita, na qual somas e débitos tendem a se corresponder. O processo de abertura foi visto por muitas empresas e investidores como um acesso rápido a um montante de capital significativo, que não necessariamente deveria encontrar correspondência em setores produtivos ou mesmo financeiros. Esta dimensão da fraude é muito difícil de pesquisar, por isso quase não é registrada na pesquisa, mas ela existe" (MARTINS, 2010, p. 45). 
imobiliário a partir do processo mesmo de expansão das incorporadoras. O boom imobiliário iniciado em 2007, portanto, continha já seus problemas próprios. E a crise dos subprime, ao mesmo tempo em que leva embora uma grande massa de capital internacional que buscava valorização dentro do país, contraditoriamente, fortalece a necessidade de tê-lo de volta para restabelecer o elo já criado entre o setor imobiliário e financeiro. A crise de 2008 serve, antes de qualquer coisa, para trazer à tona um problema já existente dentro do mercado imobiliário brasileiro.

\section{Os impactos da crise dos subprime no mercado imobiliário brasileiro}

Antes mesmo da crise dos subprime ${ }^{12}$ estourar em fins de 2008, o modelo expansionista de crescimento adotado pelas incorporadoras brasileiras com a abertura dos capitais na bolsa já mostrava claros sinais de esgotamento. Mesmo possuindo em seus conteúdos o avanço para todo o território nacional e para o chamado "segmento econômico", aparecendo, dessa forma, como um setor em amplo crescimento, essas questões críticas já podiam ser identificadas. Alguns dos sinais de tal esgotamento podem ser aqui verificados:

Produziu-se em 2008 um pico de inflação na construção (12,2 \%, o dobro do índice geral), houve falta de determinados insumos e de mão de obra especializada, casos de má gestão em algumas empresas, redução de exigências em relação ao crédito e à qualidade dos produtos, produção acima da demanda e, por fim, uma oferta acima da capacidade do crédito. A crise mundial, portanto, embora venha a agravar a situação, não está na origem dos limites para o crescimento do setor e dos problemas mencionados (ARANTES \& FIX, 2009, grifos nossos)

A retomada do crescimento só poderá ser verificada com o lançamento do Programa Minha Casa Minha Vida, em março de 2009 (como pode ser observado no gráfico abaixo), que se utiliza do suporte dos fundos públicos para salvar as incorporadoras e manter os índices positivos da economia brasileira, num movimento que intenciona realizar a reprodução fictícia do Estado nacional.

\footnotetext{
12 “O não pagamento das dívidas pelos compradores de imóveis, nos EUA, criou uma crise nas instituições do topo da pirâmide financeira, os bancos. É preciso entender aqui o crédito em sua relação social, pois com a prática do repasse das dívidas das instituições menores - e que cederam o crédito para as instituições maiores, os bancos, sob a forma de securitização - o 'conhecimento' sobre a potencialidade do pagamento da dívida se dissolve e o ritmo de pagamentos previstos não se confirma. Chamou-se crise dos subprime porque as pessoas que tomaram estes empréstimos não possuíam garantias fortes para o pagamento das dívidas, por isso eram rotuladas com sub, e só lhes restou o abandono do bem financiado, a casa" (MARTINS, 2010, p. 41-2).
} 
Cotação diária das ações de algumas incorporadoras listadas na Bovespa: de $01 / 2007$ a $11 / 2012$

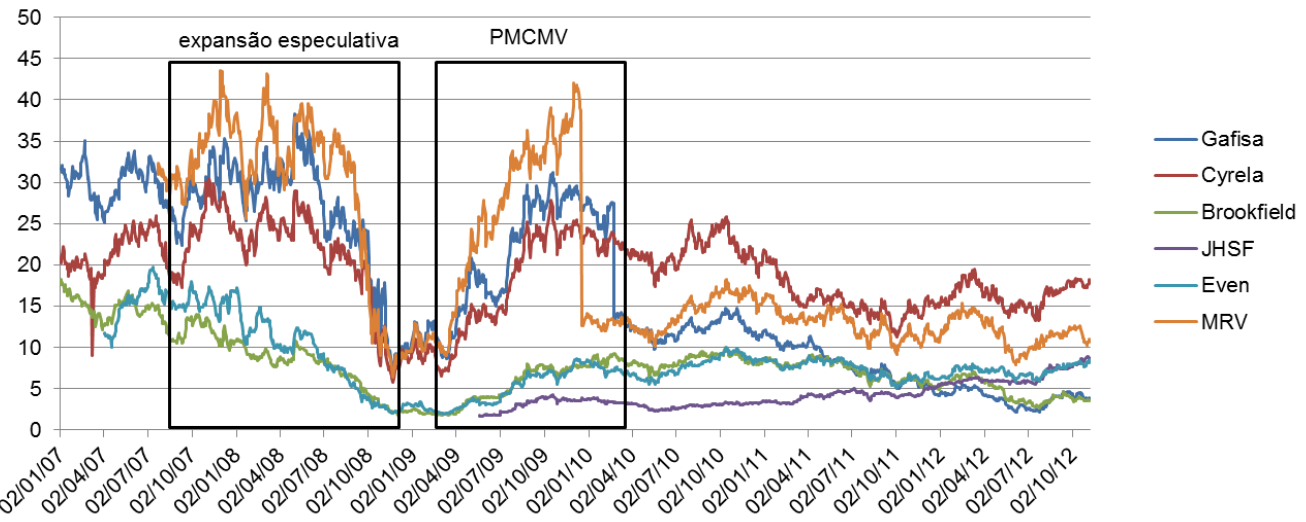

Figura 1: Cotação diária das ações de algumas incorporadoras listadas na Bovespa de 01/2007 a 11/2012.

Fonte: Simoni, 2013. Dados da Thomson Reuters.

A crise, portanto, tornou mais evidente os problemas já existentes no setor imobiliário. Mas pelo fato de ter agora em seus conteúdos a influência do capital financeiro mundial, as particularidades do setor ficam mais vulneráveis aos movimentos do capital global. A própria abertura de capital já fez essa ligação entre o capital internacional e o funcionamento interno das empresas, dando a elas a necessidade do aumento dos lançamentos como contraparte para a remuneração do capital na velocidade de remuneração do capital global. Não é à toa que esses ritmos alheios ao processo interno das incorporadoras devessem ser respeitados, uma vez que os investidores estrangeiros "(...) conformavam cerca de 70\% dos investimentos em empresas de construção civil” (MARTINS, 2010, p. 43). Na figura abaixo, por exemplo, pode-se observar um gráfico com as respostas dadas pelas incorporadoras ao mercado no momento da abertura de capitais, da crise de 2008 e do lançamento do Programa Minha Casa Minha Vida. O comportamento diferenciado entre as incorporadoras, entretanto, como se observará, se deve aos diferentes perfis de mercado que buscam atender. A MRV, por exemplo, diferentemente da Cyrela, teve seu crescimento baseado no segmento econômico, que compreende indivíduos com renda de 3 a 10 salários mínimos. Por isso um crescimento expressivo quando do anúncio do PMCMV, em março de 2009. Neste momento observa-se uma diminuição no crescimento da Cyrela, empresa que optou por não extrapolar-se dos mercados centrais de alto padrão até então. 


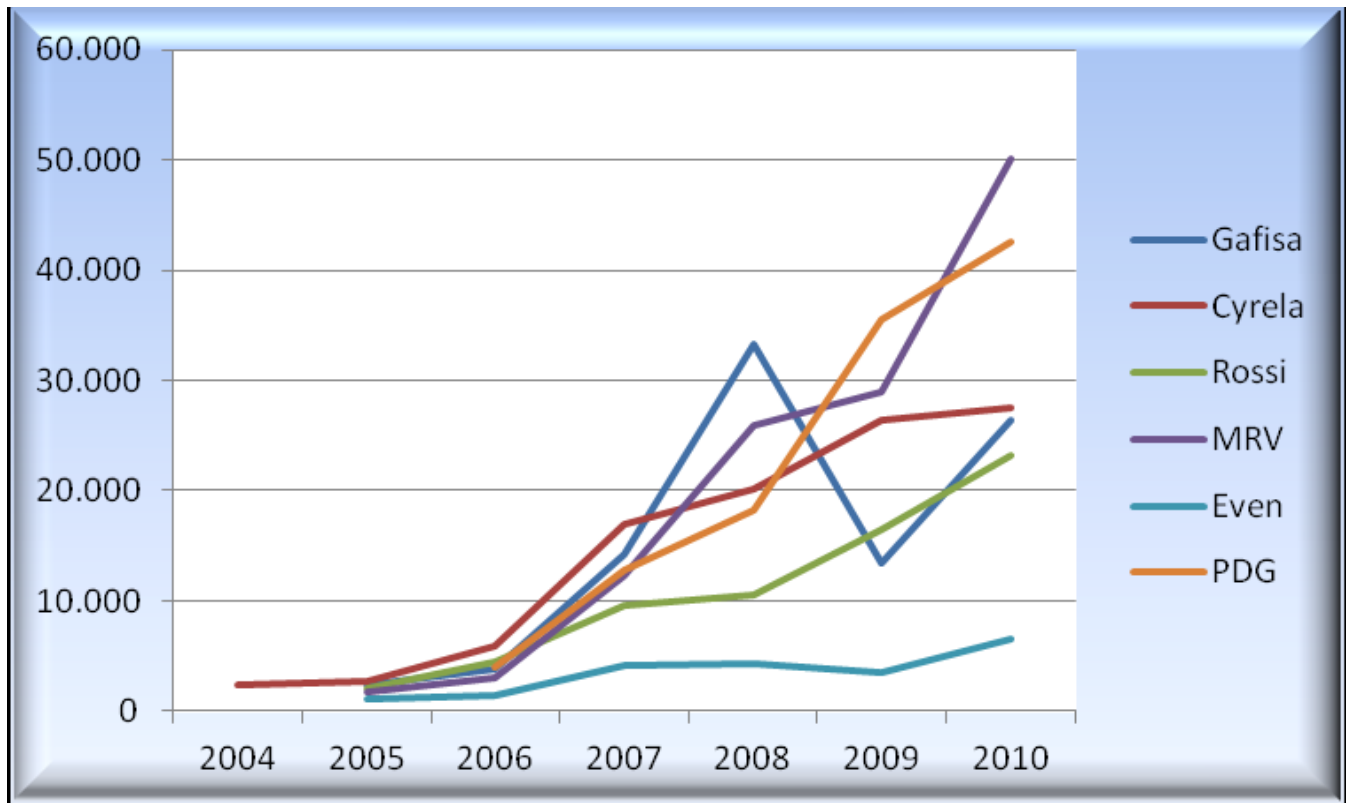

Figura 2: Unidades Lançadas por ano por empresa dentre as principais empresas do ramo (20042010).

Fonte: Simoni, 2013.

Com a crise, os investidores estrangeiros abandonam os investimentos nessas empresas e aquele processo que já descrevemos de expansão geográfica via parcerias com as empresas menores começa a se retrair. "Resta da crise também um movimento acelerado de concentração das incorporadoras, de aquisição das menores pelas maiores (...). Em junho de 2009 foram três aquisições, a Cyrela comprou a Agra, a Gafisa comprou a Tenda e a Brascan comprou a Compan." (MARTINS, 2010, p. 44) Há, dessa maneira, uma redefinição dos participantes do mercado, marcado por fusões e desaparecimentos, bem como pela centralização do capital nas grandes incorporadoras e sua consequente retração para os grandes centros.

Segundo Martins (2010, p. 45),

a absorção do impacto da recente crise americana nas IPO's brasileiras pode ser resumida como uma revisão de planos nos lançamentos imobiliários, reduzindo o número de lançamentos e projetando-os em prazos maiores, na opção pelo desenvolvimento de lançamentos imobiliários focados nos mercados mais populares, na negociação (venda) de bancos de terras adquiridos anteriormente, e na reestruturação interna das empresas, por meio, sobretudo, das demissões em massa dos setores de 'novos negócios' das incorporadoras. 
Ainda que seja crítica a reprodução desse mercado, antes mesmo da abertura dos capitais na bolsa de valores a internacionalização da crise de 2008 agrava tal processo e repercute instantaneamente nas empresas de capital aberto, com os resultados aqui vistos.

Se num primeiro momento ocorre a entrada de dinheiro em adiantamento por conta da corrida ao banco de terras, como fora anunciado no item anterior; os recursos previstos para a produção de novas unidades imobiliárias foram boicotados pela crise americana. O capital financeiro parece impor os seus ritmos ao funcionamento das incorporadoras, ao desenvolvimento das cidades e ao cotidiano urbano. Quando traz a "prosperidade", enxergamos créditos abundantes e uma aceleração nos ritmos de vida e no local de produção, a partir de um maior controle futuro das ações das incorporadoras; todavia, em tempos em que a crise se torna fenomênica, a abundância de créditos passa a ser vista como processo de endividamento geral da sociedade, entrelaçando todos os setores da economia no funcionamento crítico do capital fictício.

\section{O surgimento do Programa Minha Casa Minha Vida num contexto de 'estado de emergência econômico'}

Conforme já anunciamos, parece haver um movimento do mercado imobiliário brasileiro, de 2006 até os dias atuais, que coloca todo o território nacional como plataforma de acumulação de dinheiro do capital financeiro mundial, com reflexo no cotidiano urbano e numa produção/reprodução do espaço na escala nacional; possuindo agora em seu conteúdo a velocidade de remuneração de um capital global, alheio aos processos particulares. O Programa Minha Casa Minha Vida influenciou e continua influenciando fortemente esse movimento e:

atualmente a prática de contar com investidores financeiros [nas estruturas das incorporadoras] se acomodou como uma realidade. Esta consolidação repercute em normas e condutas das empresas e, especialmente, repercute enormemente na forma de se produzir o espaço metropolitano (MARTINS, 2010, p. 45).

Assim, a partir do que vimos até agora, concluiremos com a observação de um movimento de "expansão - retração - expansão retraída" do mercado imobiliário brasileiro dentro do período analisado. Num primeiro momento, quando da abertura dos capitais na bolsa de valores, as incorporadoras foram obrigadas a expandir-se tanto para fora dos grandes centros como para os segmentos de mais baixa renda. Esta empresa malsucedida, que teve na compra dos bancos de terras um talismã ao qual se apegar, mostrou sua face real antes mesmo da crise de 2008, trazendo à tona os problemas de acumulação internos ao setor e para muito além dele, aqui 
supracitados. A dita crise dos subprime serviu para retrair de vez a expansão desenfreada e insustentável dessas incorporadoras, uma vez que o capital internacional retirou-se desse mercado. Ocorreram demissões em massa, cortes de projetos, queda abrupta dos valores de tais empresas na Bolsa, fusões, aquisições, enfim, uma nova configuração tomou conta desse setor (MARTINS, 2010). Em meio à quebradeira e desconfiança geral, surgiu o Programa Minha Casa Minha Vida, em março de 2009, o qual aparece como uma salvação anticíclica para a economia real, mas serve, na verdade, para salvar a remuneração do capital financeiro mundial dentro das incorporadoras abaladas pela crise do setor e pela crise mundial ${ }^{13}$.

O que o PMCMV fez foi restabelecer o elo fragilizado na crise dos subprime entre o mercado imobiliário brasileiro - nas suas especificidades regionais - e os interesses de acumulação do capital financeiro mundial. As características particulares do setor voltaram a ser bem quistas internacionalmente após a criação do Pacote Habitacional, que passou a vincular as conhecidas políticas de interesse social do governo Lula ao salvamento das empresas do setor. Se a corrida cega pela captura dos land banks já não sustentava a maquiagem necessária para a captação de dinheiro em adiantamento, o governo brasileiro encontrou no pacote uma forma de atração desse capital para as incorporadoras. Assim, elas passam não mais a serem avaliadas pelo critério abstrato da formação de um banco de terras, mas sim pela capacidade em mostrar ser possível o investimento lucrativo nas mesmas, dentro de um novo contexto de crescimento econômico nacional. Na aparência de resolução da crise criada pelo próprio setor, o Estado incorpora a função de administrador da crise e utiliza-se da possibilidade de crescimento do setor imobiliário como um novo parâmetro abstrato para a captação de dinheiro em adiantamento para o próprio país.

O crescimento do setor imobiliário brasileiro engorda os índices de crescimento econômico do país medidos pelo PIB e leva confiabilidade aos investidores internacionais, não apenas para os investimentos no setor, mas também na dívida pública brasileira. A crise de acumulação de dinheiro é a chance para o país enquadrar-se num esquema mundial de acumulação crítica. É melhor acumular em crise que não acumular.

Agora, ao invés da expansão produtiva e de mercados, essas empresas buscavam associar a fama que o programa recebeu internacionalmente às suas próprias condições de desfrutarem do bom momento da economia nacional e das aclamadas políticas públicas que favoreciam o segmento. O objetivo dessa vinculação publicitária era criar a imagem que conduziria o entendimento do investidor a relacionar as internacionalmente reconhecidas

13 “(...) o pacote teve seu caráter emergencial muito mais associado aos mercados financeiros e imobiliários do que à economia real em geral” (SIMONI, 2013, p. 239). 
políticas sociais do governo Lula às condições de crescimento do segmento, fazendo com que o mercado imobiliário pudesse, aparentemente, surgir como um importante mediador entre o 'crescimento econômico nacional' e a possibilidade de investimentos lucrativos. Mas, na prática, o segmento se tornava o vínculo efetivo entre o fundo público brasileiro e o grande capital internacional. Como resultado dessa estratégia, a relação da ampliação do banco de terras com a escala do Programa Minha Casa Minha Vida se evidencia (SIMONI, 2013, p. 248-9).

Se num primeiro momento o mercado imobiliário brasileiro vincula-se "autonomamente" ao capital financeiro mundial; num segundo momento é o Estado que estabelece essa relação necessária ao colocar o fundo público à disposição da remuneração do capital internacional. O Programa Minha Casa Minha Vida surge não só como salvador de um setor fragilizado, mas como a brecha encontrada pelo próprio Estado para reproduzir-se ficticiamente. Ele vem salvar o setor das "ameaças do capital fictício"? Não, ao contrário. Ele aparece para salvar o país da falta de uma acumulação fictícia. O vínculo atual necessário entre o Estado nacional, incorporadoras, capital financeiro mundial e indivíduos é o próprio capital portador de capital fictício. Numa jogada de mestre, o Estado encontra uma nova maneira de inserir-se na forma de acumulação mundial (baseado em dívidas), de salvar as empresas de uma quebradeira geral, de remunerar o capital financeiro e, finalmente, de colocar toda uma população - através da retomada da ideologia da casa própria num esquema de endividamento de longo prazo.

Os conteúdos de um cotidiano urbano caracterizado pelo "trabalho futuro" em uma sociedade que apresenta a crise do trabalho como uma de suas prerrogativas ainda está por ser desvelado. No olho do furacão, o que podemos constatar é uma estranheza geral, sob a qual se encara o presente para saldar o passado e se posterga ao futuro a esperança de não desmoralizar-se com as dívidas do consumo atual. Agora, além das pequenas prestações acumuladas das dívidas contraídas com as Casas Bahia, Lojas Marabrás, entre tantas outras, que em alguns meses se saldava, tem-se a prestação da mercadoria habitação como uma constante ${ }^{14}$, ad eternum, que endivida os indivíduos, de forma generalizada, com o Estado. Cria-se uma ligação importante e perigosa. É bom ficarmos atentos ao nível de repressão que este "novo" credor, possuidor do monopólio da violência na sociedade, pode exercer sobre toda uma população endividada.

14 O Programa Minha Casa Minha Vida libera financiamentos com prazos máximos de 35 anos, obrigando que a dívida não comprometa mais que $30 \%$ da remuneração familiar. No entanto, como vimos em trabalhos de campo para a elaboração do presente texto, o Programa parece dar um tiro certeiro no processo de endividamento geral da sociedade, uma vez que não considera que, com esses $30 \%$ fixos, boa parte da população compromete quase $3 / 4$ de toda a sua remuneração com o total das dívidas. 
O lançamento do Programa Minha Casa Minha Vida impôs fortes mudanças na avaliação das empresas de capital aberto ${ }^{15}$. Ele promove uma nova expansão dos ganhos nas incorporadoras e da influência destas sobre o território nacional, mas na forma de uma "expansão retraída". O céu não é mais o limite, pois a crise anterior já havia colocado as nuvens no meio do caminho.

O PMCMV tende, assim, a restaurar um padrão de realização do investimento em mercados regionais, ao menos pelo período considerado necessário para minimizar as possíveis e efetivas perdas que resultam do próprio conjunto de estratégias passadas do segmento, com o agravante e a justificativa dados pela crise. Aqui, mais um exemplo de estado de emergência econômico instaurado em nome da acumulação financeira. Valendo-se de uma estratégia que buscava legitimidade a partir da sempre urgente resolução de um dos problemas mais caros para a história da desigualdade de oportunidades na sociedade brasileira, o lançamento do Programa Minha Casa Minha Vida não se diferenciava dos demais pelo fundo retórico que lhe dava sustentação, mas sim pelos montantes envolvidos e pelos seus vínculos com uma economia financeirizada (SIMONI, 2013, p. 248)

No plano ideológico, o que parece importar é que se consiga apresentar à sociedade uma situação sempre crítica, mas sem explicitar os nexos e fundamentos da própria crise. Com a crise (habitacional, econômica, ecológica) iminente, as resoluções emergenciais são facilmente aceitas e ganham inclusive suporte de parte dos movimentos sociais e de todas as esferas da sociedade. O contexto de surgimento do PMCMV serve, portanto, para amenizar os impactos da crise dos subprime no mercado interno, da eterna crise habitacional brasileira e da falta de liquidez que acometia as incorporadoras naquele momento.

Ainda assim, o programa foi pensado para durar um período de tempo limitado (...), porque sua função, mais do que instaurar uma nova dinâmica expansionista, estava ligada ao salvamento do segmento como uma importante porta de entrada para o capital estrangeiro (SIMONI, 2013, p. 251).

\footnotetext{
15 "O pacote surge como salvação para o setor que estava entrando em crise profunda, por fatores internos e externos. No primeiro semestre de 2009, (...), o setor da construção lidera disparado (58\% acima do segundo colocado) a alta na Bolsa de Valores, impulsionado pelo anúncio do pacote habitacional, segundo afirmam diversos analistas. As empresas que mais se beneficiaram foram as voltadas ao mercado econômico (Tenda, MRV e Rodobens), que apenas nos dois meses após o anúncio do pacote tiveram ganhos especulativos de 126\% em suas ações na Bolsa, refletindo a expectativa de ganhos futuros" (ARANTES \& FIX, 2009)
} 
Está dada, dessa forma, a ligação entre o Estado, os indivíduos e as incorporadoras, num contexto de endividamento geral da sociedade e de mudanças nas formas urbanas de sobrevivência. Com o intuito de seguir reproduzindo-se ficticiamente, o Estado brasileiro cria um programa com a justificativa emergencial da crise, o qual permite a volta dos capitais internacionais para o país através da vinculação de um setor em potencial expansão ao crescimento econômico, ao déficit habitacional e a menores taxas de desemprego. O Programa Minha Casa Minha Vida estendeu-se do "I" ao "II" e pode estender-se infinitamente, desde que continue remunerando o capital financeiro internacional e permitindo ao país receber estes capitais para a própria reprodução. Assim que ele não servir mais a tais fins deixará de existir e outro setor com novas dinâmicas sustentará este mecanismo. Neste momento, a cidade e o urbano se depararão mais evidentemente com o negativo de todo esse processo, com os impactos de uma "urbanização crítica" (DAMIANI, 2004). Então, a dinâmica do urbano dependerá mais da carência do pacote que da esperança de seus efeitos positivos futuros.

A intervenção do fundo público fez as incorporadoras retornarem à sua dinâmica expansiva, porém em ritmo menor. Com essa "expansão retraída", que recolocaria os níveis de acumulação nos patamares anteriores à "retração" evidenciada pela crise, “(...) as grandes empresas voltaram-se mais para suas 'praças' originais, concentrando-se novamente nos grandes mercados centrais" (SIMONI, 2013, p. 262). Essa dinâmica reforça a ideia de expansão territorial dada a partir da concentração do capital nos grandes centros. Isso fez com que se criassem boatos a respeito da total concentração dos mercados regionais nas mãos das empresas centrais a partir da abertura dos IPO's e principalmente com o lançamento do PMCMV. No entanto, isso não se confirma, uma vez que “(...) esse desfecho que deixou espaço ainda para as pequenas incorporadoras se deve a um padrão de incorporação que não se ajusta às características do novo mercado" (SIMONI, 2013, p. 254). A problemática já apresentada a respeito das particularidades das pequenas empresas locais e de suas parcerias necessárias com as grandes empresas do centro dinâmico da economia evidencia, ao mesmo tempo, a impossibilidade de se ter nas primeiras a velocidade de remuneração do capital financeiro e a necessidade de se utilizar delas para manter a credibilidade da captação de recursos em adiantamento para o setor concentrado no centro. O que se coloca é que são apenas algumas das principais grandes empresas que, juntamente com as regionais, atuam no mercado nacional como um todo para fazer valer a expansão do PMCMV. Enquanto parece importar apenas que essa dinâmica como um todo se faça crível aos olhos dos investidores internacionais, ou seja, que ela deixe clara a capacidade de solvência do Estado nacional por trás desse processo, passando por cima de algumas particularidades do próprio setor - por exemplo, o grau de endividamento das incorporadoras, do próprio Estado nacional via PMCMV e dos indivíduos colocados nesse esquema de longo prazo. Tal qual já observamos anteriormente, os números são frios e são eles que valem como parâmetro de avaliação do capital financeiro 
internacional. O restante é estrutural e não entra na conta dos avaliadores financeiros, mas deve ser posto, que seja por nós, na conta da população submetida a esse processo.

O boom imobiliário verificado no Brasil parece, portanto, ser resposta de uma dinâmica anterior ao PMCMV, já descrita neste trabalho. Eis, portanto, a razão de ser do PMCMV, com algumas ressalvas que faremos a seguir:

Em termos gerais, ele [o PMCMV] apenas sustentou a realização de capitais já comprometidos com um modelo pouco sustentável que havia, em pouco tempo, encontrado seus termos críticos. O fundamento expansionista desse mercado, assim como seus limites, deve ser buscado mais em outras estratégias. A compra de terrenos como artifício de demonstração encontrou limites claros nas já tradicionais 'praças' de atuação dessas grandes incorporadoras. A perspectiva de aumento do número de unidades lançadas e a concorrência nos mercados centrais foram, em período de captação de recursos por meio da oferta de ações, outras componentes importantes nesse surto expansionista. Assim, as grandes empresas que haviam realizado seus IPO's acabaram por se comprometer com lançamentos futuros fora dos centros dinâmicos da economia nacional sem ainda terem as condições de venda e realização de seus produtos na velocidade demandada pelo fugaz mercado de capitais. Esse comportamento de perfil especulativo e sem fundamento na economia real iria exigir do Estado o exercício de sua função de garantidor de última instância, o que se deu também dentro de uma lógica financeirizada de intervenção. As projeções de crescimento, elemento crucial para o investidor em carteira ou de tipo fundamentalista, tornaram-se aqui a moeda de troca pelo capital de giro. A falta de fundamentos dessas apostas tornou essa corrida expansionista a base da formação de um capital fictício de curta duração e é nesse momento que o PMCMV aparece como medida anticíclica. A realização do capital fictício do ramo das incorporadoras delimitou assim o campo de atuação do programa (SIMONI, 2013, p. 253, grifos nossos).

O que Simoni chama de formação de um capital fictício é, em nossa compreensão, o capital fictício já em crise, ou seja, no único momento em que ele aparece. Por dentro desse raciocínio e pensando numa dialética existente entre o Estado e o mercado, o que o Estado faz é salvar o capital fictício para que ele continue acumulando criticamente em seu mecanismo de acumulação de dinheiro e desvalorização do valor simultaneamente, ao invés de eliminá-lo para que o capital volte a acumular "normalmente". Esconder a sua crise através da constante subida aos céus de um dinheiro sem valor faz parte da sua forma de acumular e o fato de 
sua forma crítica não aparecer a todo instante não quer dizer que ele não se reproduza criticamente. Ele, agora, só é garantidor em última instância da economia real, na medida em que salvá-la significa reproduzir-se ficticiamente. No momento em que o capital financeiro mundial em busca de valorização não encontrar mais no mercado imobiliário uma forma de alavancar-se, o Estado nacional brasileiro terá de escolher um novo setor capaz de reproduzi-lo ficticiamente: cana, soja, petróleo, eucalipto, qual queira. Assim, e para finalizar, o governo não se utilizou do PMCMV simplesmente para salvar o setor de uma pretensa ameaça do capital fictício à economia brasileira, mas, ao contrário, utilizou-se dele para se inserir num esquema de acumulação global baseado no capital fictício. A estratégia passa por encontrar setores que, numa dialética entre acumulação e crise, ajudem no processo de formação do Estado nacional brasileiro em bases fictícias.

No caso específico que estamos tratando, o PMCMV serviu como uma máquina aceleradora do tempo, colocando para girar aquele capital sobreacumulado (HARVEY, 2004) do primeiro momento de expansão do setor imobiliário, o qual havia ficado aprisionado pela necessidade de realização daquela alta captação de dinheiro quando da abertura dos capitais na bolsa, porém agora tem seu ritmo mais atrelado à velocidade de remuneração do capital financeiro internacional.

\section{Considerações Finais}

O presente artigo buscou apresentar o caminho do mercado imobiliário brasileiro desde a abertura de capital das incorporadoras, nos anos de 2006-2007, até a implementação emergencial do Programa Minha Casa Minha Vida, no início de 2009. A partir da passagem turbulenta desse mercado por crises internas e pela crise de 2008, foi estabelecido um forte elo entre as particularidades do setor e o movimento do capital financeiro mundial atrelado a ele. A necessária remuneração desse dinheiro em busca de mais dinheiro do mercado financeiro dentro das incorporadoras impôs a estas, ao Estado nacional e aos indivíduos um ritmo mais azeitado ao deste capital transnacional do que às determinações próprias de cada um deles.

A fim de salvar as incorporadoras nacionais que estavam prestes a quebrar por uma crise no setor, seguida da crise mundial de 2008, o governo brasileiro lançou o Programa Minha Casa Minha Vida e atrelou, de forma inédita e crítica, a resolução de um dos problemas mais caros à sociedade brasileira (a questão da habitação) ao salvamento do grande capital financeiro internacional ligado a essas incorporadoras. O resgate do capital fictício nessas empresas constituiu-se pela criação de um forte elo entre os fundos públicos e o capital internacional, que teve como importante resultado a concretização de um Estado nacional em bases fictícias.

Para tanto, o governo precisou expandir os créditos - as dívidas, melhor dizendo e permitir o aumento do endividamento de toda a sociedade brasileira. Propõe-se, 
aqui, uma inversão: a naturalização da dívida surge através da necessidade de expansão dos créditos. Um novo cenário está montado, a saber, as empresas, Estado e indivíduos fazem parte agora de um esquema de endividamento geral da sociedade, sem o qual a remuneração do capital financeiro - com conteúdos cada vez mais marcados pelo capital fictício - não poderia se garantir.

O que temos de novo no cenário, em relação a outros planos habitacionais ou formas de endividamento, é que agora um grande montante da população brasileira está endividado sob outros parâmetros. Seu credor dos trinta longos anos de financiamento do PMCMV é o Estado nacional brasileiro, único agente de contratos que possui o monopólio da violência; e a velocidade necessária de remuneração do capital já não é estatal, mas pautada pela velocidade do capital financeiro internacional. A relação com o tempo e o espaço no cotidiano urbano sofrerá alterações importantes no momento em que o capital financeiro alcança todas as esferas da sociedade.

Tais mudanças impõem ao cotidiano novas formas de pobreza, para além daquela absoluta e miserável a qual estamos acostumados enquanto fenômeno. Agora o alcance ao cotidiano e a inclusão no que se chamaria de "pobreza urbana" (DAMIANI, 2011), pressupõem algo mais sutil e de difícil percepção, trata-se de ampliar o conceito de pobreza, incluindo-se o sujeito endividado no longo prazo pelo PMCMV.

\section{Bibliografia}

ARANTES, P. (2007) Estado de sítio. São Paulo: Boitempo.

; FIX, M. (1995) 'Minha Casa, Minha Vida': o pacote habitacional de Lula. Correio da Cidadania, 30 jul. 2009. Não paginado. Disponível em: $<$ http://www.correiocidadania.com.br/index.php?option=com_content\&view=catego ry\&layout=blog\&id=66\&Itemid=171. Acessado em: 10 mar. 2013.

BOTELHO, A. (2007) O Urbano em Fragmentos: a produção do espaço e da moradia pelas práticas do setor imobiliário. São Paulo: Annablume.

CARLOS, A. F. A. (2012) Da "organização" à "produção" do espaço no movimento do pensamento geográfico. In: CARLOS, A. F. A.; SOUZA, M. L.; SPOSITO, M. E. B. (Org.) A produção do espaço urbano: agentes e processos, escalas e desafios. São Paulo: Contexto. pp. 53-74.

DAMIANI, A. L. (1995) A cidade (des)ordenada e o cotidiano. RDG - Revista do Departamento de Geografia, v. 9, USP. São Paulo. Disponível em: < http://www.revistas.usp.br/rdg/article/view/53696/57659>. Acessado em 01 jul. 2013.

- (2004) Urbanização Crítica e Situação Geográfica a partir da Metrópole de São Paulo. In: CARLOS, A. F. A.; OLIVEIRA, A. U. (Org.) Geografias de São Paulo: Representação e crise da Metrópole. São Paulo: Contexto. pp. 19-58. 
FEREIRA, J. S. W. (2010) Cidades para poucos ou para todos? Impasses da democratização das cidades no Brasil e os riscos de um urbanismo às avessas. In: OLIVEIRA, F.; BRAGA, R.; RIZEK, C. (Org.) Hegemonia às avessas: economia política e cultura na era da servidão financeira. São Paulo: Boitempo.

HARVEY, D. (1992) Condição Pós-Moderna: uma pesquisa sobre as Origens da Mudança Cultural. São Paulo: Loyola.

. (2011) O Enigma do Capital e as Crises do Capitalismo. São Paulo: Boitempo.

. (1990) Los Limites Del Capitalismo y La Teoria Marxista. México: Fondo de Cultura Económica. . (2004) O Novo Imperialismo. São Paulo: Loyola.

HÖFIG, B. Algumas observações sobre o movimento $D-D^{\prime} e$ a crise contemporânea. Não publicado.

KURZ, R. (1995) A ascensão do dinheiro aos céus. Revista Krisis, n ${ }^{\circ}$ 16-17. Disponível em: <http://obeco.planetaclix.pt/rkurz101.htm>. Acesso em: maio 2008.

. (1999) O colapso da modernização: da derrocada do socialismo de caserna à crise da economia mundial. 5. ed. São Paulo: Paz e Terra.

LEFEBVRE, H. (1991) A Vida Cotidiana no Mundo Moderno. São Paulo: Editora Ática.

. (2008) A Revolução Urbana. Belo Horizonte: Editora UFMG.

(1969) O Direito à Cidade. São Paulo: Documentos.

MARTINS, F. E. da S. (2010) A re(produção) social da escala metropolitana: um estudo sobre a abertura de capitais nas incorporadoras e sobre o endividamento imobiliário urbano em São Paulo. Tese (Doutorado em Geografia Humana) Faculdade de Filosofia, Letras e Ciências Humanas, Universidade de São Paulo. São Paulo

MARX, K. (1983) O Capital - Crítica da Economia Política. 5 Volumes. São Paulo: Abril Cultural. (Série Os Economistas).

. (1982) Para a Crítica da Economia Política. São Paulo: Abril Cultural. (Série Os Economistas).

OLIVEIRA, F. (2003) Crítica a Razão Dualista/O Ornitorrinco. São Paulo: Boitempo. Boitempo.

(2008) Noiva da Revolução/Elegia para uma Re(li)gião. São Paulo: . (1998) O Surgimento do Antivalor. In: Os Direitos do Antivalor: a economia política da hegemonia imperfeita. Petrópolis: Vozes. (Coleção Zero à Esquerda).

SANTOS, C. R. S. (2013) A Nova Centralidade da Metrópole: da urbanização expandida à acumulação especificamente urbana. Tese (Doutorado em Geografia Humana) - Faculdade de Filosofia, Letras e Ciências Humanas, Universidade de São Paulo. São Paulo. 
Data de submissão: 04/05/2015.

Data de aceite: 01/08/2015. 